\title{
Algunas consideraciones en torno a la Bioética y la Investigación Científica Biomédica
}

Los cambios en la ciencia y la tecnología, el aumento vertiginoso del conocimiento en Medicina, la necesidad de buscar avances en materia de investigación cientifica biomédica y el reconocimiento de derechos humanos en declaraciones internacionales, han ido presionando a los gobiernos al reconocimiento e incorporación de tales derechos, en los sistemas jurídicos de los diversos países. En lo que atañe a la investigación y sea atendiendo a los requerimientos éticos desde la perspectiva de los sujetos de la investigación, o desde la perspectiva del investigador, ha ido surgiendo una Ética Internacional de la Investigación, que recogida por el Derecho, ha llegado a ser el marco jurídico aplicable a la investigación científica biomédica. Así, en un mundo globalizado como el actual, la aplicación de máximas universalmente aceptadas a una investigación también globalizada, resulta evidente y necesaria. En este sentido, la investigación más frecuente, se refiere a ensayos clínicos en estudios relativos a medicamentos, promovidos y financiados por la industria farmacéutica.

Ha habido también, una traslación del polo de atención de los problemas surgidos de la investigación biomédica, desde aspectos esenciales relativos a evitar el sufrimiento humano, a problemas actuales derivados del resguardo de la confidencialidad de los datos médicos, para proteger la intimidad de las personas y evitar la discriminación. Si bien sigue siendo un objetivo el avance del conocimiento científico en pos de la ciencia y en bien de la Humanidad, los inconmensurables beneficios económicos que la incorporación de un nuevo medicamento produce en el mercado, pueden ser comparables a los datos recogidos o a los surgidos o que pueden surgir de las muestras biológicas provenientes de las investigaciones. Los primeros requerimientos basados en derechos fundamentales, como el respeto a la dignidad de la persona, su integridad y su derecho a la intimidad, entre otros, se han centrado en uno más actual cual es la protección de los datos de carácter personal y específicamente de los datos sensibles, que dicen relación con la salud y el derecho a la no discriminación. Más decisiva aún, es la información genética, que requiere una protección especial, derivada de la trascendencia que la divulgación de tal información puede producir en lo cultural, familiar y social, además de lo individual de las personas.

Las normas éticas internacionales, plantean máximas de aplicación general, cuya concreción en los paises del tercer mundo, puede merecer ajustes derivados de factores culturales y de idiosincrasia, que impiden a las personas ejercer su autonomía, sea porque no se sienten culturalmente dueños, sea porque la organización comunitaria ha entregado el ejercicio pleno a los jefes de éstas, como puede suceder por ejemplo, en comunidades indígenas o bien, sea que los niveles de marginalidad, pobreza y marginación del sistema sanitario y social, los torna vulnerables.

La investigación biomédica, es tributaria del ejercicio de la práctica médica. En este sentido enfrentó el paternalismo médico, que rigió desde la Medicina Hipocrática. Ésta consideraba a los enfermos como incapaces morales y sin capacidad y facultad para decidir respecto de su enfermedad, con la contrapartida también que logra una suerte de equilibrio, basado en una medicina "maternalista" con énfasis en el cuidado del médico por hacer soportable y llevadera la enfermedad, en la benevolencia, en la gracia, en la búsqueda del bien del paciente. ${ }^{1}$ Correspondió también esto a la mirada "naturalista" en que el hombre es parte de la naturaleza que tiene su propio orden natural. El descubrimiento de la autonomía del individuo es un aporte de la modernidad en que el hombre ya no es un ser natural, sino un ser moral y como tal protagonista y artifice de su propia moralidad. ${ }^{2}$ Las miradas autonomistas imperantes en la actualidad provienen de la Ética liberal, con el reconocimiento de las primeras tablas de derechos humanos, que fueron el origen del Derecho Constitucional moderno y de la moderna Ética de la Investigación. Por su parte, la Bioética que constituye un saber interdisciplinario, entre la ética y las ciencias de la vida, ha permitido la incorporación de valores morales a las ciencias de la Salud, a la práctica cotidiana de 
los profesionales sanitarios y a la investigación biomédica, además de facilitar espacios de reflexión entre diversos actores de una sociedad, necesarios en una sociedad democrática.

La forma en que las normas éticas han enfrentado la participación de sujetos humanos en la investigación biomédica, es un indice de la evolución a que nos hemos venido refiriendo y a su análisis nos ocuparemos, sobre la base de algunas declaraciones internacionales en Ética de la Investigación. La evolución se observa a través de la institución del "consentimiento informado", que precisamente muestra los distintos enfoques que el reconocimiento de libertades y el perfeccionamiento del ejercicio de la autonomía de las personas, ha ido presentado respecto de la investigación.

El Código de Nuremberg, del 20 de Agosto de $1947^{3}$ es resultado del juicio realizado a los médicos nazis que habian realizado experimentos atroces, atentatorios a la vida y a la dignidad humana, en prisioneros y personas vulnerables en Alemania. El énfasis de este cuerpo normativo, está dado por la participación voluntaria del sujeto en la investigación, al señalar que "es absolutamente esencial el consentimiento voluntario del sujeto humano", asegurándosele también la libertad para poner fin al experimento durante el desarrollo del mismo, "si ha alcanzado el estado físico y mental en el cual le parece a él que es imposible continuarlo". Aún cuando pudiere parecer que el ejercicio de la autonomía es pobre-al exigir sólo consentimiento voluntario, al no exigir información previa y seguridad que el consentimiento sea otorgado en forma libre, sin coerción o presiones- resultó un avance importante en el desarrollo teórico moral de la materia en los círculos científicos. La historia demuestra también, que la sola existencia de cuerpos normativos, no otorga seguridad de cumplimiento; y es así como, la comunidad mundial ha sido testigo y con seguridad continuará siéndolo, de violaciones a los principios éticos en investigación.

En el curso de los años siguientes, la propia comunidad médica estimó necesario establecer diferencias en lo que se refiere a la investigación en seres humanos con propósitos meramente científicos, no terapéuticos y aquella en que el experimento tiene objetivo esencialmente terapéutico para el sujeto, en este caso, el paciente. Así, la Asamblea Médica Mundial aprobó en 1964, la Declaración de Helsinki, que contiene recomendaciones para guiar la investigación en seres humanos. ${ }^{4}$ La primera prevención de la Declaración, establece la obligatoriedad que la investigación en un ser humano, respete los principios morales y cientificos que justifican la investigación en medicina humana, que se base “... en exámenes de laboratorio, pruebas sobre animales o sobre cualquier otro dato científicamente establecido". En cuanto al consentimiento del sujeto de investigación, la declaración distingue entre investigación terapéutica o no terapéutica. En lo que atañe a la primera, el médico tiene la libertad para recurrir.. "si a su juicio tal (nuevo método terapéutico) ofrece una seria esperanza de salvar la vida, restablecer la salud o aliviar los sufrimientos del paciente". Respecto del consentimiento del sujeto, la exigencia es muy débil, por cuanto el médico debe obtener el "consentimiento libre y esclarecido" ... "en lo posible y de acuerdo con la psicología del paciente..." "En caso de incapacidad fisica el permiso del representante legal sustituye el del paciente".

Frente a lo anterior, la investigación no terapéutica impone al médico la función de proteger la vida y la salud del sujeto sometido a experimentación. Asimismo, exige el consentimiento libre y lúcido del sujeto, debiendo encontrarse éste ... "en un estado mental, físico y legal que lo capacite para ejercer plenamente su facultad de elegir y de decidir". Es de observar que las exigencias son mayores respecto del voluntario sano, lo que sigue aconteciendo hasta la fecha. La Declaración ha tenido sucesivas modificaciones, en 1975, 1983, 1989, 1996 y 2000, ésta última aprobada en la Asamblea Médica Mundial realizada en Edimburgo, Escocia. Los cambios introducidos en estos años, han sido numerosos y no es posible extender este editorial para referirse a ellos particularizadamente. Sin embargo, una de las diferencias más importantes, radica en el hecho que está dirigida no sólo a médicos, sino también a ... "otras personas que realizan investigación en seres humanos". Reconoce que la investigación médica "está sujeta a normas que sirven para promover el respeto a todos los seres humanos y para proteger su salud y sus derechos individuales" estableciendo como deber del médico, la protección de la vida, la salud, la intimidad, y la dignidad del ser humano. Enfatiza la protección especial que requieren las poblaciones vulnerables y quienes se encuentran en desventajas médicas o económicas; $y$ distingue entre los que no pueden otorgar o rechazar el consentimiento por sí mismos, a los que pueden otorgarlo bajo presión "y a los que tienen la investigación combinada con atención médica". Los participantes en una investigación, deben ser voluntarios e informados adecuadamente, acerca de los objetivos, métodos, fuentes de 
financiamiento, posibles conflictos de intereses, afiliaciones institucionales del investigador, beneficios esperados, riesgos previsibles e incomodidades derivadas del experimento, así como el derecho a retirarse del experimento sin sanción. La obligación del médico, es asegurarse de la comprensión de la información y sólo después, obtener el consentimiento informado. Si existiese relación de dependencia entre el médico y el probando, si consintiere bajo presión, el consentimiento deberá obtenerlo otro médico informado, que no esté en las condiciones anteriores. Considera la protección del medio ambiente y el bienestar de los animales de experimentación. Incluye el tratamiento de las publicaciones que son resultado de la investigación. A este respecto impone obligaciones a autores y editores. A los primeros, respecto de la exactitud de los datos y resultados, al deber de publicar resultados positivos y negativos o ponerlos a disposición del público, de "citar la fuente de financiamiento, afiliaciones institucionales y cualquier posible conflicto de intereses". Respecto de los editores, les impone el deber de no aceptar informes que no se ciñan a la Declaración ${ }^{6}$. En lo relativo a la investigación médica combinada con atención médica y uso de placebo, ha existido gran debate e interpretaciones respecto del comparador con el procedimiento nuevo a que se refiere el párrafo 29 de la Declaración 7 .

Coetáneamente y con posterioridad, se han incorporado otros cuerpos normativos y declaraciones internacionales, que especificamente o en un contexto mayor, se han ocupado de la investigación biomédica en seres humanos. Entre éstos están las "Pautas Éticas Internacionales para la Investigación Biomédica en Seres Humanos" cuya primera versión es de 1993 y la más reciente de 2002, que sustituyó a la anterior ${ }^{8}$ y que proviene del Consejo de Organizaciones Internacionales de las Ciencias Médicas, en colaboración con la Organización Mundial de la Salud.

En nuestro país, se ha aprobado recientemente la ley que regula la investigación científica en el ser humano, su genoma y prohibe la clonación humana ${ }^{9}$.

El texto mismo de la ley es escueto; y, reconociendo la libertad de investigación, establece límites para ella. Así, la investigación debe proteger la vida de los seres humanos a partir de la concepción, su integridad fisica y psíquica y su diversidad e identidad genética. La investigación, como toda otra actividad, tampoco puede infringir el respeto a los derechos y libertades esenciales que emanan de la naturaleza humana. Estos derechos pueden estar reconocidos por la Constitución Politica o por tratados internacionales vigentes, ratificados por Chile.

En relación con la investigación, se prohibe: toda práctica eugenésica (salvo la consejería genética); la clonación; y la destrucción de embriones para obtener células troncales para el cultivo de tejidos y órganos.

Desde el punto de vista del sujeto de investigación, éste debe previamente consentir en participar en ésta, en forma expresa, libre e informada. El consentimiento informado, requiere que la persona que deba prestarlo, haya recibido información adecuada, suficiente y comprensible de los aspectos esenciales de la investigación: su finalidad, beneficios, riesgos y procedimientos o tratamientos alternativos. El participante en la investigación, debe también ser advertido del derecho a no otorgar consentimiento o a revocarlo en cualquier momento, sin recibir sanción por ello. La ley no señala que la obligación de informar al participante, sea del investigador. El consentimiento debe constar en un acta que deben suscribir el participante, el director responsable de la investigación y el director del establecimiento donde deba desarrollarse la investigación. Ésta ultima exigencia, producirá problemas en su aplicación práctica, en razón de las múltiples obligaciones que corresponden a un director, como resultado de lo cual el cumplimiento de esta obligación, será meramente formal, frente a la imposibilidad de delegarla, al no haberlo autorizado la ley. El director autoriza la investigación científica previo informe favorable del Comité Ético Científico y suscribe el acta, como ministro de fe. La ley entrega a un reglamento, la determinación del comité al cual corresponde emitir el informe previo. El reglamento debe dictarlo el Ministerio de Salud, debiendo también, contener las normas que complementen o desarrollen los contenidos de la ley.

Se crea, entre otras, la figura penal de falsificación del acta de consentimiento o de uso malicioso de un acta falsa; y de desarrollo de un proyecto de investigación científica sin contar con las autorizaciones previstas en la ley, con sanciones de reclusión, multa, suspensión y prohibición absoluta del ejercicio profesional, respectivamente.

Frente a la interrogante respecto del panorama normativo futuro en el pais, surge la incógnita respecto del reglamento a dictarse por el Ministerio de Salud. Por su parte, el trabajo de los Comités Ético Científico, en beneficio del bienestar de los sujetos de la investigación biomédica, pueda desarrollarse en nuestro país, sobre la base de la aplicación de la normativa ética internacio- 
nal sobre la materia, que dada su extensión y comprehensividad, no resulta posible incluir en un reglamento o norma técnica ministerial. La riqueza de la aplicación, estará dada precisamente por el adecuado trabajo de los comités de bioética, que en Chile acumulan una experiencia de casi un decenio.

Desde otro punto de vista, en una sociedad democrática, la adopción de decisiones y el tratamiento de las cuestiones bioéticas, se debería realizar sobre la base de la promoción del profesionalismo, de la honestidad, la integridad y la transparencia en la adopción de decisiones en tales materias; de un diálogo permanente entre las personas, los profesionales interesados y la sociedad en su conjunto; $y$, promoviendo un "debate público pluralista e informado en que se expresen todas las opiniones pertinentes" 8 .

La Ley de Investigación comentada someramente en este editorial, considera la creación de una Comisión Nacional de Bioética, lo que es un buen augurio en el sentido señalado.

María Angélica Sotomayor Saavedra Abogada, Directora Jurídica y Miembro del Comité de Ética, Facultad de Medicina, Universidad de Chile

\section{Bibliografía}

1.- GRACIA-GUILLÉN D. Fundamentos de Bioética, Ed. Eudema S.A., Madrid.1989 págs 42-4.

2.- Ibid. págs 122-123.

3.- $\quad$ The Nuremberg Code, Science, N.Y. 1964 , 143; 553.

4.- XVIII Asamblea Médica Mundial, 1964: Declaración de Helsinki. Rev Méd Chile 1967; 95: 281-2.

5.- Ibid. Declaración de Helsinki Acápites I $\mathrm{N}^{\circ} 1$, II N $\mathrm{N}^{\mathrm{o}} 1$, III $\mathrm{n}^{\mathrm{os}} .3$ y $3 \mathrm{~b}$ ).

6.- Declaración de Helsinki, 52 ${ }^{\mathrm{a}}$ Asamblea General de la
Asociación Médica Mundial, Escocia octubre, 2000.

7.- CARNÉ-CLADELLAS X. Uso de Placebos en Ensayos Clínicos. Revista Humanitas On Line N ${ }^{\circ}$ 7; 2006. Fundación Medicina y Humanidades Médicas www. humanitas.es

8.- Consejo de Organizaciones Internacionales de las Ciencias Médicas (CIOMS): Pautas Éticas Internacionales para la Investigación Biomédica en Seres Humanos Ginebra 2002 Programa Regional de Bioética OPS/ OMS Santiago 95-1001, 2003.

9.- Ley No 20.120. Diario Oficial 22-9-2006. 